\title{
Complutum
}

ISSN: 1131-6993

\section{Etnoarqueología y arte rupestre: potencial, perspectivas y ética}

\author{
Inés Domingo ${ }^{1}$; Claire $\mathrm{Smith}^{2}$; S.K. May ${ }^{3}$
}

Recibido: 29 de junio de 2016 / Aceptado: 6 de marzo de 2017

Resumen. Este artículo reflexiona de manera crítica sobre el potencial de la investigación etnoarqueológica para contribuir a la comprensión de los procesos de creación y el uso del arte rupestre. A diferencia de la mayor parte de los estudios arqueológicos, centrados en el estudio de materiales y objetos separados de sus autores desde hace mucho tiempo, la investigación etnoarqueológica implica trabajar con personas y restos contemporáneos y requiere una atención a sensibilidades culturales que pueden ser notablemente distintas a las del investigador. Por ello, también reflexionaremos sobre las implicaciones éticas y metodológicas de este tipo de investigación, que a nuestro juicio pueden resultar particularmente relevantes para los investigadores españoles, dada la falta de formación etnoarqueológica de las universidades españolas. Las reflexiones presentadas en este artículo son fruto de una larga experiencia colaborando y aprendiendo de los Ancianos y de los artistas de varias comunidades Aborígenes situadas en el oeste de la Tierra de Arnhem y en la región de Barunga (Territorio del Norte, Australia).

Palabras clave: Etnoarqueologia; Arte rupestre; Ética; Australia.

\section{[en] Ethnoarchaeology and Rock Art: Potential, Perspectives and Ethics}

Abstract. This paper critically reflects on the potential of ethnoarchaeological research to contribute to our understanding of the creation and use of rock art. While most archaeology focuses on material culture separated through time from their makers, ethnoarchaeological research involves working with people and contemporary objects and requires an attention to cultural sensitivities that may differ significantly from those of the researcher. We also reflect, therefore, on the ethics of ethnoarchaeological research. This is particularly relevant to Spanish researchers given the lack of training available in this area at Spanish universities. The reflections summarized in this paper are built upon our long-term experience collaborating and learning from Aboriginal Elders and artists from several communities in western Arnhem Land and the Barunga region of the Northern Territory (Australia).

Keywords: Ethnoarchaeology; Rock Art; Ethics; Australia.

Sumario. 1. Introducción. 2. ¿Qué entendemos por etnoarqueología? 3. ¿Cómo se aplica hoy la etnoarqueología al estudio del arte rupestre? 4. Aproximación al área de estudio. 5. Aplicaciones prácticas de la etnoarqueología al estudio del arte rupestre. 6. Conclusiones.

Cómo citar: Domingo, I. et al. (2017): Etnoarqueología y arte rupestre: potencial, perspectivas y ética. Complutum, 28(2): 285-305.

\section{Introducción}

En España, como en cualquier lugar en el que los autores del arte rupestre y sus descendientes directos han desaparecido hace milenios, la arqueología juega un papel fundamental en el análisis del arte rupestre antiguo. A través de métodos cuantitativos y cualitativos se intenta dar respuesta a las preguntas cuándo, quién, cómo o por qué fue creado el arte rupestre. Y

\footnotetext{
ICREA. Universitat de Barcelona. SERP. Secció de Prehistòria i Arqueologia (España)

E-mail: ines.domingo@ub.edu

2 Flinders University. Department of Archaeology (Australia)

E-mail: Claire.smith@flinders.edu.au

3 ANU (The Australian National University). School of Archaeology and Anthropology, Canberra (Australia)

E-mail: sally.may@anu.edu.au
} 
para ello se recurre a la descripción sistemática de los motivos, los paneles, los yacimientos y su entorno, a la arqueometría y a la realización de excavaciones arqueológicas que nos permitan aproximarnos al contexto de creación. Sin embargo, en un entorno puramente arqueológico, los mecanismos y las prácticas sociales, el simbolismo o el significado de muchos aspectos de la producción y el consumo del arte rupestre se han desvanecido, dejando una gran cantidad de preguntas sin respuesta:

- ¿Quién pinta, por qué y para qué?

- ¿A quién va dirigido?

- ¿Hasta qué punto podemos interpretar el arte de otra cultura?

- ¿Reproduce hechos reales o imaginarios?

- ¿Por qué se seleccionan unos lugares y no otros?

Estas y otras preguntas sólo encuentran respuesta cuando nos desplazamos a lugares donde el arte rupestre aun forma parte de una cultura viva, proporcionando un contexto inigualable para reflexionar sobre algunas de estas cuestiones, y comprobar la validez de métodos púramente arqueológicos de aproximación al arte rupestre antiguo. Uno de los lugares donde las conexiones ancestrales entre el arte rupestre y la población actual se mantienen todavía hoy es el norte de Australia (Chaloupka 1993; Taçon y Garde 1995; Domingo y May 2008; May y Domingo 2010; Domingo 2011; Brady et al. 2016). Y es allí donde se enmarcan nuestras investigaciones.

El recurso al paralelismo etnográfico en la investigación española del arte rupestre no es una novedad. De hecho, ya desde el descubrimiento de Altamira se recurre a la información etnográfica para proponer hipótesis de interpretación (Ripoll 1986; Moro y González 2005; Domingo et al., en prensa). Lo que resulta más novedoso es la aproximación etnoarqueológica al arte rupestre, es decir, la observación y el estudio directo entre poblaciones vivas. Este tipo de aproximación debe partir necesariamente de unas reflexiones previas sobre las implicaciones éticas y metodológicas que envuelve trabajar con poblaciones vivas, y en nuestro caso con poblaciones Aborígenes de la Tierra de Arnhem. Creemos que este tipo de reflexiones pueden resultar de interés a investigadores que se planteen desarrollar iniciativas similares en el siglo XXI y que carezcan de formación etnográfica. En Australia, por el contrario, la aproximación etnoarqueológica al arte rupestre es más habitual, cuando se trata de proyectos enfocados al estudio del patrimonio Aborigen. Es más, en estos proyectos ya no se recurre simplemente a la observación de poblaciones Aborígenes, en las que estos actúan como meros 'informantes', sino más bien a la colaboración con estas poblaciones, que hoy incluso forman parte o pasan a liderar este tipo de proyectos como investigadores (Wilson 2007: 321-322). Este nuevo enfoque se engloba dentro de lo que entendemos hoy por arqueología comunitaria o arqueología pública (ver por ejemplo, Greer et al. 2002; Greer 2014). Esta arqueología colaborativa tiene en cuenta los factores socio-políticos que afectan a las comunidades Aborígenes y reconoce sus luchas históricas y actuales (McNiven y Russell 2005). Nuestro aproximación etnoarqueológica al arte rupestre del Oeste y Sur de la Tierra de Arnhem se englobaría dentro de esta corriente de investigación.

Las reflexiones que presenta este artículo son fruto de una larga colaboración y aprendizaje de los ancianos Aborígenes y artistas de varias comunidades del Oeste de la Tierra de Arnhem y de la región de Barunga (Territorio del Norte, Australia). Resaltamos este aspecto, al entender que los resultados de cualquier investigación etnoarqueológica están influidos por la capacidad de los investigadores de comprometerse con la comunidad y desarrollar confianza mutua y relaciones a largo plazo (véase también Greer et al. 2002: 268; Field et al. 2000: 44; McNiven y Russell 2005; Wilson 2007; Greer 2014). C. Smith desarrolla sus investigaciones en la región de Barunga desde la década de 1990, cuando inició su tesis doctoral sobre estilo y arte Aborigen de la región (Smith 1996). Algunos de sus primeros profesores y mentores Aborígenes han fallecido recientemente y ahora trabaja con sus descendientes (Smith et al, en prensa). S. May ha trabajado de manera continuada en el oeste de la Tierra de Arnhem (Gunbalanya, Parque Nacional de Kakadu, territorio Mirarr y la Cordillera Wellington) desde el año 2000, cuando inició su investigación doctoral sobre arte Aborigen (May 2006). I. Domingo se unió al equipo de C. Smith en 2001, y ha estado trabajando con Smith y May de manera continua desde 2006. En sus investigaciones ha desarrollado un interés especial por explorar los aspectos sociales $\mathrm{y}$ territoriales del arte rupestre en un entorno etnoarqueológico. 
Nuestro objetivo con este artículo es ir más allá de una presentación de los resultados de nuestras investigaciones etnoarqueológicas en el Oeste de la Tierra de Arnhem y la región de Barunga, para ofrecer una reflexión crítica sobre las implicaciones éticas y metodológicas de nuestra investigación etnoarqueológica, así como su potencial y limitaciones para hacer inferencias sobre el arte rupestre antiguo, ya sea de Australia como de cualquier otro lugar del planeta.

\section{2. ¿Qué entendemos por etnoarqueología?}

Este trabajo no pretende ofrecer una revisión historiográfica sobre el uso de la etnoarqueología en la construcción del conocimiento científico sobre grupos humanos pasados y presentes (ver por ejemplo Hernando 1995; David y Kramer 2001; Politis 2002; GonzálezRuibal 2007). Pero sí incidiremos brevemente en la definición de etnoarqueología que sirve de marco de referencia a nuestra investigación.

La definición y los usos de la etnoarqueología han cambiado desde las primeras etapas, en que se definía como una estrategia de investigación que pretendía contribuir a la interpretación arqueológica del pasado a través de la analogía y que se basaba en la observación de sociedades vivas y su relación con la cultura material. Hoy no podemos negar la contribución de la analogía a la investigación arqueológica. Esta contribución no ha estado exenta de críticas (Wylie 1985), pero estas críticas han favorecido la reflexión sobre el potencial y las limitaciones de la etnoarqueología en la actualidad.

Parafraseando a Politis, la etnoarqueología implica la recogida sistemática de información sobre la dimensión material de la conducta humana entre poblaciones vivas, y para ello requiere, entre otras cosas, la realización de trabajo de campo mediante observación participante (Politis 2002 y 2015). Esta definición excluiría del concepto de etnoarqueología la utilización exclusivamente de registros etnográficos, al no haber interacción con poblaciones vivas. No obstante, esto no quita valor a la información etnográfica antigua, a la que nosotras recurrimos en múltiples ocasiones (Domingo 2011; Wright et al 2014; Domingo et al. 2016).

Existen diferencias significativas entre el concepto actual de etnoarqueología y el con- cepto "romántico" de la antropología victoriana de finales del siglo XVIII y principios del XIX, que vale la pena discutir. Los antropólogos de este periodo describían a los Aborígenes como anclados en el pasado y como fósiles vivientes de etapas "primitivas" de la civilización. Frente a ese concepción discriminatoria de los otros, los europeos asumían que ellos en cambio, tenían historia y estaban en un proceso continuo de cambio y evolución (Wolf 1982; Clifford 1988: 220-1; Griffiths 1996: 24-25; May 2000; May 2009). Este desacierto generó la idea de que viajar a lugares con poblaciones con desarrollos económicos o tecnológicos que recordaban a los de nuestros antepasados occidentales era como viajar al pasado. Y un buen ejemplo de ello es Australia (para una síntesis crítica ver McNiven y Russell 2005). A finales de los siglos XVIII y XIX el mundo occidental consideraba a Australia como una especie de "colonia penal paleontológica" (Nietzche 1974: 24), como un museo en el que observar el pasado en un estado natural. Esta idea posiblemente tenía su origen en el concepto de darwinismo social.

En el momento del contacto con los primeros europeos, los grupos humanos que habitaban el territorio australiano eran cazarecolectores y utilizaban artefactos de piedra, hueso y materiales perecederos que llevaron a describirlos de manera recurrente como "hombres de la Edad de Piedra", tanto en publicaciones (Fig. 1) (Vizard 1930; Mountford 1949 y 1963; Idriess 1963: XII, etc.) como en documentales (The Stone Age Men of Australia. 1933. Con la expedición Mackay Aerial Survey Expedition a Australia Central. Descrita por el Comandante H T Bennett DSO, FRGS, RN@British Pathe). Este tipo de interpretaciones dieron pie al uso de la analogía para comparar el paleolítico europeo con estas poblaciones Aborígenes consideradas como "prehistóricas" y "primitivas" (véase, por ejemplo, Tylor 1865; Spencer 1901; Taylor 1927). Pero este tipo de enfoque ignora las distancias temporales y culturales que median entre ambas culturas, niega tanto la evolución como la modernidad de poblaciones que comparten el mundo con nosotros en el siglo XXI, e no tiene en cuenta que las poblaciones Aborígenes también tienen historia y son fruto de la evolución y el cambio, como demuestran el registro arqueológico y artístico. Estos usos de la etnoarqueología son criticados y excluidos en nuestra investigación. 


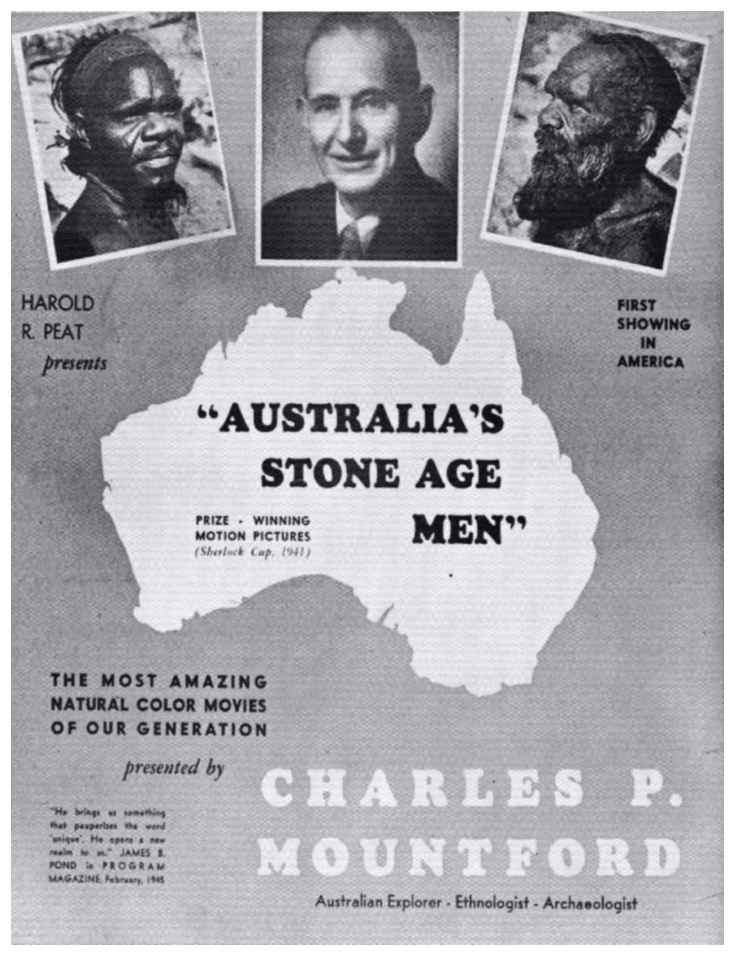

Figura 1. Portada del folleto de propaganda de la gira de conferencias de Mountford en los Estados Unidos entre 1945 y 1946 (Lamshed 1972: 120).

Desde aquellas primeras etapas la atención por la etnoarqueología ha ido fluctuado a lo largo de los siglos XX y XXI (ver Van Reybrouck 2012), con viejas y nuevas ideas que siguen formando parte de los debates actuales.

Con la "Nueva Arqueología" la investigación arqueológica pasa de la mera reconstrucción de las formas de vida pasadas a la explicación del cambio (Binford 1967). Y en este contexto la etnoarqueología resurgió, después de un período de relativo silencio, como una forma de comprobar hipótesis. El razonamiento analógico volvió a ser criticado por diversos investigadores (Gould 1978; Wylie 1985) pero su idea de utilizar la etnoarqueología para poner a prueba la validez de hipótesis continua vigente en la actualidad. Más tarde, con el desarrollo de la arqueología contextual, la etnoarqueología adquirió nuevos valores como herramienta para proponer interpretaciones alternativas de la cultura material y resaltar su papel, no sólo como un producto, sino como productor de acciones sociales. Para nosotros estos continúan siendo los dos papeles claves de los estudios etnoarqueológicos actuales.

La etnoarqueología es, y debe seguir siendo, mucho más que el estudio del presente para comprender el pasado. Es una herramienta para observar y analizar la cultura material (objetos y estructuras) en un contexto vivo (desde la producción al consumo) en una sociedad determinada. La etnoarqueología nos permite observar las interacciones diarias entre los humanos y los objetos, que dejan de ser materiales inertes para transformarse en agentes activos de las prácticas sociales, económicas y/o culturales. También demuestra la invisibilidad arqueológica de muchos aspectos de las culturas humanas (como aquellos producidos con materiales perecederos, así como el patrimonio inmaterial, que incluye la música, las canciones, las danzas, las ceremonias, valores culturales adscritos a paisajes y lugares sin evidencias antrópicas, etc. tan vinculados a las prácticas artísticas que son objeto de este estudio). Por último, es fundamental para entender otras formas de pensamiento y de relación con el entorno alejadas de las occidentales, que nos pueden aportar enfoques de interpretación distintos y sugerir preguntas de investigación que de otra manera nunca hubiéramos imaginado (Hernando 1995: 28; Politis 2002). Estas observaciones son de gran importancia para la construcción de teorías y para desarrollar enfoques más críticos en el estudio arqueológico del arte rupestre antiguo. Nuestra aproximación etnoarqueológica al arte rupestre está determinada por esta última definición de etnoarqueología.

\section{3. ¿Cómo se aplica hoy la etnoarqueología al estudio del arte rupestre?}

En teoría, la investigación etnoarqueológica se basa en observaciones realizadas en el marco de sociedades vivas, con una actitud de mínima interferencia y con un proyecto de investigación previamente definido (Politis 2014). En nuestro acercamiento al arte rupestre del Oeste de la Tierra de Arnhem y la región de Barunga, los conocimientos Aborígenes sobre la producción, el uso y el significado del arte, y nuestra experiencia arqueológica (hipótesis, teorías y métodos) se funden para revelar la complejidad de esta forma de comunicación visual, utilizada durante milenios como marcador territorial y como vehículo de comunicación para transmitir información sobre la sociedad, la cultura y las normas de comportamiento.

Nuestra aproximación etnoarqueológica al arte rupestre va más allá de la analogía, que ha 
sido mal utilizada con anterioridad para sugerir marcos interpretativos simplistas para el arte rupestre prehistórico europeo principalmente (El totemismo de Frazer 1922 y Tylor 1871, La mágica de caza de Reinach 1903, teoría que fue posteriormente ampliada y popularizada por Breuil 1952; las teorías del chamanismo de Jean-Clottes y Lewis Willians 1996; etc.). Estas analogías parten del principio de que las culturas Aborígenes eran fósiles vivientes y, por tanto, sus interpretaciones sobre el arte actual podían ser directamente extrapoladas al arte paleolítico europeo. Sin embargo, como hemos defendido con anterioridad, las culturas Aborígenes no son estáticas sino que están en proceso de cambio, de convertirse en la manifestación futura de esa cultura (Smith 2008: 92), y como tal, estamos completamente de acuerdo en que el conocimiento etnográfico actual no se puede utilizar para interpretar directamente el arte rupestre antiguo, ni en Australia ni fuera de allí (véase la discusión en Tacon 1989; Layton 1992; Rosenfield 1997; Chippindale y Tacon 1998).

Sin embargo, la etnoarqueología puede jugar un papel importante en la interpretación arqueológica del arte rupestre, como herramienta para testar y perfeccionar teorías y métodos arqueológicos, y para construir enfoques teóricos y metodológicos más críticos para abordar el estudio del arte rupestre antiguo. Además, nuestro objetivo también incluye avanzar en el conocimiento del papel del arte rupestre en las sociedades Aborígenes presentes y pasadas en nuestras áreas de estudio (May 2006 y 2008; Domingo 2011; Domingo et al. 2016).

\section{Aproximación al área de estudio}

Nuestra investigación se ha centrado en diversos territorios del Oeste de la Tierra de Arnhem, pero los datos presentados en este trabajo proceden fundamentalmente de las comunidades Aborígenes de Gunbalanya o Oenpelli y de la región de Barunga (oeste y sur de la Tierra de Arnhem, Territorio del Norte, Australia) (Fig. 2). Esta región tiene una historia reciente compleja. Las primeras interacciones con poblaciones foráneas se producen en el siglo XVII cuando los Makassar de Indonesia frecuentaban las costas australianas en busca de pepino de mar y de otros artículos de intercambio. A ellos seguirán las primeras visitas esporádicas de exploradores europeos y finalmente la llegada de colonos británicos y misioneros cristianos, que se asentarían de manera permanente (ej. Smith 2004; May et al. 2015).

El área de estudio aparece con frecuencia mencionada al hablar de la primera colonización de Sahul, al albergar algunos de los yacimientos que han proporcionado las ocupaciones humanas más antiguas de Australia (50-55 ka BP) (Clarkson et al. 2015).

Cuando llegaron los primeros europeos las poblaciones Aborígenes de estos territorios mostraban una gran diversidad cultural, con diferencias significativas a nivel lingüístico, en las prácticas sociales y en la cultura material. El mapa de David R. Horton de la Australia Aborigen es una buena prueba de ello (http:// aiatsis.gov.au/explore/articles/aiatsis-map-indigenous-australia). Se trataba de poblaciones nómadas o seminómadas, pero fuertemente conectadas con determinadas partes del territorio. Estas poblaciones se organizaban en grupos flexibles de familias extensas y practicaban una cierta movilidad en busca de recursos estacionales (Chaloupka 1981). Su tecnología era relativamente modesta, pero presentaban uno de los comportamientos socio-culturales más sofisticados registrados por los antropólogos, con una importante inversión de su tiempo en prácticas culturales, como el arte, la religión y las leyes (Morphy 1991; Smith 2004). Las ceremonias jugaban un papel importante en la transmisión del conocimiento, en el intercambio de ideas y de materias primas, en la formación de las nuevas generaciones, en los rituales vinculados a los diversos estadios de la vida, y en definitiva en asegurar la continuidad de las prácticas socio-culturales. En estas ceremonias tienen un papel fundamental las creencias religiosas, las narraciones históricas y las leyes ancestrales que se celebran y transmiten a través de relatos, canciones y diversas formas de arte (corporal, mueble y rupestre), en las que también se integran la danza y la música (véase, por ejemplo, Berndt y Berndt 1970; Morphy 1991; Taylor 1996; Smith 2004). La secuencia artística rupestre de estos territorios tiene además un valor histórico incalculable, al recoger de forma gráfica los cambios que se producen en la historia Aborigen con anterioridad y con posterioridad al contacto con los europeos. Podríamos hablar sin duda de un archivo visual histórico que ilustra la versión Aborigen de esa historia (ej. May y Domingo 2010; Domingo 2011; Taçon y May 2013; May el at. 2015). A diferencia de otros territo- 


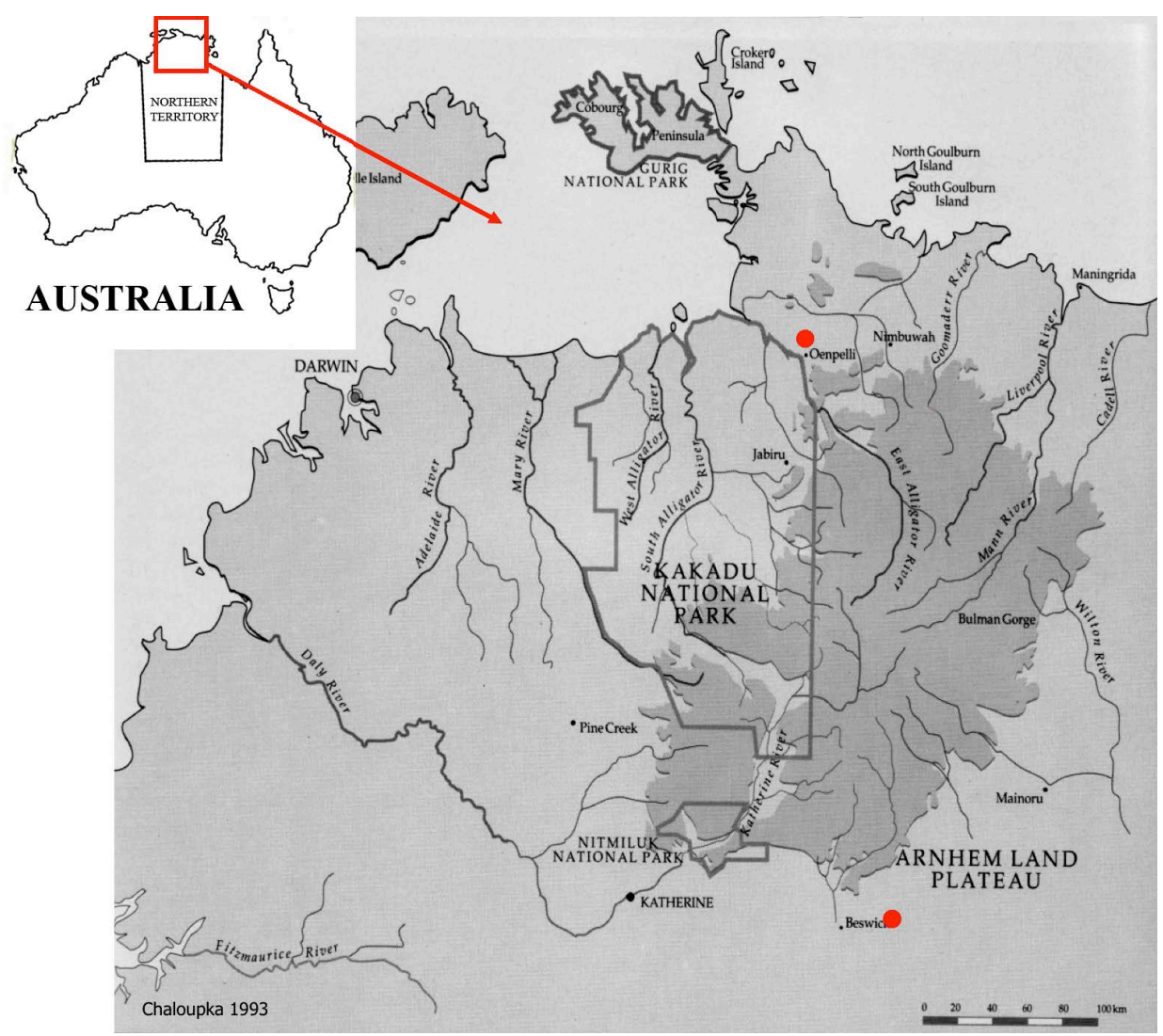

Figura 2. Localización de las áreas de estudio.

rios australianos, donde la llegada de los europeos tuvo impactos demoledores tanto a nivel demográfico como cultural, tanto la tierra de Arnhem como la región de Barunga fueron declarados reservas Aborígenes en la década de 1930. Está declaración atenuó el impacto de la invasión europea, facilitando cierta continuidad cultural (las lenguas y las ceremonias se siguen practicando), el mantenimiento de sus conexiones ancestrales con el territorios y la producción de arte rupestre. En momentos de interacción cultural difíciles una de las reacciones que se suelen producir es el refuerzo de la propia identidad (véase, por ejemplo, Taçon 2008) y en el área de estudio este elemento ha sido clave para reforzar la continuidad de las prácticas artísticas (Taylor 1996; Domingo y May 2008; May 2008).

En algunas partes de Australia, una de las obligaciones de los guardianes del territorio era la de pintar o repintar, o en otras palabras, la de renovar los lugares con arte rupestre (Taçon 1989). Esta actividad quedaba en manos exclusivamente de individuos emparentados con cada uno de estos lugares por descendencia, es decir, los miembros del clan local al que pertenecen las tierras (Smith 1996; Layton 2006). Es importante destacar que el retoque del arte rupestre no era una tradición generalizada en todo el territorio australiano, sino de determinadas regiones. En el Oeste de la Tierra de Arnhem, por ejemplo, para reavivar el valor cultural de un lugar es raro que los artistas 'retocasen' motivos deteriorados, sino que añadían nuevas representaciones a las ya existentes. La dislocación cultural producto de la invasión europea provocó una drástica reducción de estas prácticas. Del mismo modo los desplazamientos de población provocaron que en algunos lugares los grupos Aborígenes se vieran privados del acceso a sus territorios ancestrales. En la actualidad, en algunos lugares, los nuevos guardianes cuidan de sitios o motivos rupestres que fueron creados por clanes ya extinguidos. A pesar de los cambios, los conocimientos ancestrales se siguen transmitiendo a las nuevas generaciones por medio de ceremonias, danzas, canciones y relatos que tienen su representación gráfica en el arte rupestre, y en la actualidad sobre todo en 
formatos portátiles, tales como pinturas sobre corteza de árbol o sobre papel (Taylor 1996; May 2006).

Es interesante destacar que a pesar de que la producción rupestre es casi inexistente, el arte rupestre del "territorio" de un artista es todavía hoy una fuente de inspiración para la mayoría de los artistas de la parte Occidental de la Tierra de Arnhem. Del mismo modo, algunos de los que hoy son Ancianos, aprendieron a pintar sobre soportes pétreos de sus antecesores, como Paddy Compass Namatbara o Bardayal (May 2006: 62) o, como Peter Manabaru. Ambos pintaron arte rupestre con anterioridad. Además, existen derechos perdurables sobre los diseños, los motivos o las historias que cada artista puede pintar de acuerdo a su lugar de origen o condición social. El derecho a representar un motivo particular, o grupo de motivos, se hereda y/o se gana (véase, por ejemplo, Taylor 1996). Por lo tanto los motivos, los temas y los diseños todavía codifican la identidad de la persona, así como su lugar en la sociedad, en el espacio y en el tiempo (May y Domingo 2010). Todo esto nos ha proporcionado un entorno único para explorar algunas cuestiones acerca de la producción y el consumo del arte rupestre de la mano de algunos de los últimos artistas rupestres y sus descendientes directos.

\section{Metodología y principios éticos de nues- tra aproximación etnoarqueológica al arte rupestre}

Nuestra investigación sobre arte rupestre en la Tierra de Arnhem y la región de Barunga combina el enfoque arqueológico más tradicional (descripción y cuantificación, documentación digital, análisis arqueométricos y análisis del contexto arqueológico) con métodos derivados de otras ciencias sociales como la etnografía, la antropología y la sociología (observación, observación participativa, conversación y entrevistas dirigidas) para entender las interpretaciones y las prácticas de las poblaciones Aborígenes en lo que se refiere a los contextos de producción y uso del arte rupestre (Fig. 3).

Las entrevistas se llevan a cabo tanto en los yacimientos con arte rupestre, como en el entorno de la comunidad. En este caso se utilizan fotografías y documentación digital para ilustrar nuestras preguntas (Fig. 4). Durante el registro de testimonios orales optamos por la estrategia de no interferencia para no influir en la interpretación del entrevistado. Tampoco se les ofrecen interpretaciones alternativas que pudieran haber sido documentadas con anterioridad (May y Domingo 2010: 38).

Cuando nos enfrentamos a un estudio puramente arqueológico del arte rupestre tratamos únicamente con muestras materiales $\mathrm{y}$, por tanto, podemos decidir libremente el tema, las estrategias, los métodos y el tiempo a invertir en la investigación. Sin embargo, cuando nos trasladamos a un entorno etnoarqueológico no podemos actuar como meros observadores externos de otra cultura, es decir, llegar, observar, sacar nuestras propias conclusiones y marcharnos. En un contexto etnoarqueológico hay una interacción continua y un intercambio de conocimientos y beneficios. Las personas con las que trabajamos están tan interesadas en el aprendizaje mutuo y en la obtención de beneficios como nosotros.

La diferencia principal en un contexto etnoarqueológico es que pasamos de trabajar con objetos a trabajar con objetos y personas. Esto implica cierta pérdida de control sobre la situación, ya que el trabajo está condicionado por las agendas y necesidades de todos los agentes implicados. Como consecuencia, cada temporada de campo es un proceso fluido, y no podemos anticipar con total seguridad los planes y el tiempo. Es cierto que esto nos obliga a renunciar a un cierto nivel de control sobre el trabajo, pero a cambio ganamos experiencias socio-culturales muy valiosas que pueden ser utilizadas para interpretar otros aspectos socioculturales, tanto del pasado como del presente.

Además, si bien nosotras lideramos la investigación e incluimos nuestros propios conocimientos en los proyectos etnoarqueológicos, somos conscientes de que la mayor parte del conocimiento primario es aportado por las poblaciones Aborígenes con las que trabajamos, que también tienen derechos sobre su propiedad intelectual, su tiempo y sobre los resultados de la investigación. Ambos agentes son esenciales para la obtención de resultados en nuestra investigación y contribuyen a una "sopa intelectual" que reformula dos tradiciones intelectuales y dos corpus de conocimiento diferentes (Smith et al. en prensa). Y por tanto, ambos tienen que obtener beneficios (Smith 2008), para evitar situaciones previas vividas en el área de estudio en las que las poblaciones Aborígenes fueron privadas de los resultados de las investigaciones llevadas a 


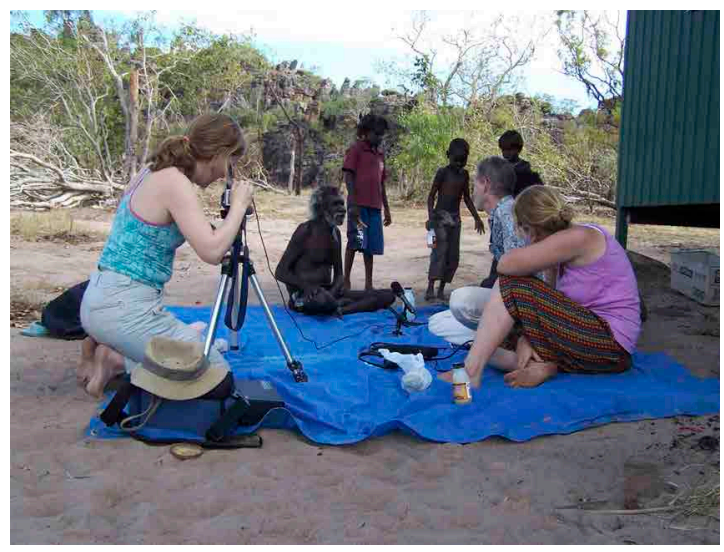

Figura 3. Inés Domingo, Sally May y el lingüista Murray Garde documentando historias orales con Thompson Yulidjirri y su familia.

cabo en sus territorios (ver por ejemplo, May et al. 2005).

Nuestra investigación etnoarqueológica se ha visto modelada por una serie de principios éticos y requisitos culturales, que compartimos en estas líneas para reflexionar sobre las implicaciones de este tipo de trabajos en el área de estudio. Es cierto que muchos de estos principios son conocidos en la etnografía y la antropología contemporánea (ver por ejemplo Bernard 2011; Lecompte y Schensul 2015), pero los arqueólogos no siempre estamos familiarizados con ellos, especialmente en aquellos países en los que la formación etnoarqueológica es escasa. Entre ellos destacaremos los siguientes puntos:

a. Tiempo de inducción para familiarizarse con los protocolos culturales apropiados

b. Identificar a la/s persona/s adecuada/s para trabajar con ella/s

c. Adaptación a los conceptos de tiempo Aborígenes

d. Flexibilidad frente a lo inesperado

e. Aprender cuándo es apropiado preguntar

f. Entender que no todo es publicable

\section{a. Tiempo de inducción}

Como en cualquier situación en la que no estamos familiarizados con una cultura, en un entorno etnoarqueológico tenemos que planificar un tiempo de inducción para aprender qué es culturalmente apropiado. Y aunque puede pa-

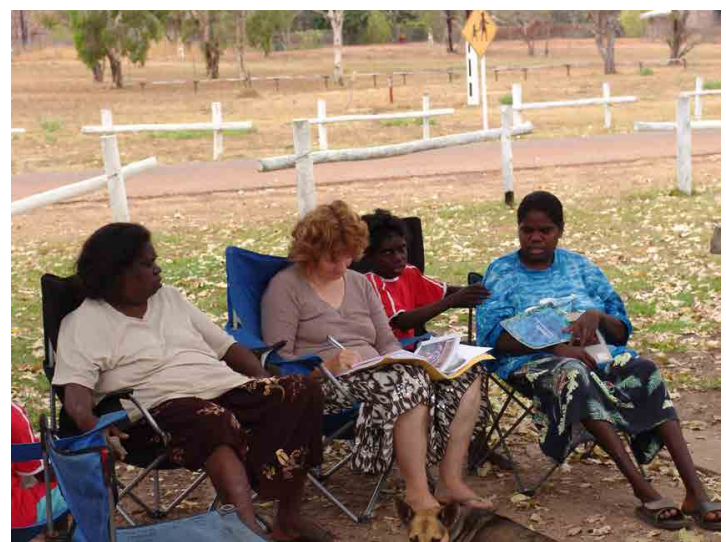

Figura 4. Claire Smith entrevistando a Rachel Willika.

recer simple, en la práctica no lo es, ya que las poblaciones Aborígenes y las sociedades occidentales podemos tener visiones distintas del mundo (Smith 2008). Es fundamental mostrar un respeto por los valores culturales que forman parte del sistema de conocimientos y creencias de los pueblos Aborígenes. Por tanto, para trabajar en un entorno Aborigen tuvimos que aprender con quién podíamos hablar, cuándo y cómo era apropiado hacer preguntas, dónde podíamos ir solas, dónde era necesario ir acompañadas por una persona Aborigen, y dónde no teníamos permiso para ir en absoluto, etc. Cosas que nos parecían normales en nuestra cultura resultaron ser inapropiadas para las poblaciones con las que trabajamos. Por ejemplo, mientras que en España es de mala educación evitar la mirada de alguien cuando te habla, entre los Aborígenes de algunas zonas de la tierra de Arnhem ocurre todo lo contrario, ya que para ellos mirar a alguien directamente a los ojos es intrusivo y desafiante, y absolutamente inadecuado si esa persona es del sexo opuesto. Si bien algunas de estas cuestiones nos pueden parecer detalles sin importancia, pueden marcar la diferencia en nuestras interacciones con las poblaciones Aborígenes.

\section{b. Identificar a la/s persona/s adecuada/s para trabajar con ella/s}

Este es un componente esencial del trabajo de campo etnoarqueológico, ya que en cualquier sociedad no todas las personas tienen el mismo nivel de conocimiento sobre distintos temas. Entre los Aborígenes australianos el acceso al 
conocimiento es gradual y depende del grado de iniciación y la categoría social (edad, sexo, etc) del individuo (Taylor 1996). Dos de nosotras (C. S. y S. M.) tuvieron que establecer nuevas relaciones con las comunidades con las que trabajamos y durante el proceso fueron tuteladas por Ancianos Aborígenes. Por el contrario la investigación de I.D. se benefició del trabajo y las relaciones preexistentes de sus predecesoras (C.S. y S.M.), lo que sin duda favoreció y aceleró su tiempo de inducción.

La respuesta a la pregunta "con quién trabajar" no estaba únicamente en nuestras manos sino que fueron los Ancianos Aborígenes los que nos orientaron hacia el grupo social más afín a nuestra situación. Por ejemplo, cuando C. S. empezó su investigación iba acompañada de su marido, Gary Jackson y su hijo, por entonces bebé. Teniendo en cuenta esa situación familiar la Anciana y Propietaria Tradicional, Phyllis Wiynjorroc, les dirigió hacia otra pareja, también marido y mujer, Peter Manabaru y Lily Willika, que además eran guardianes claves en este territorio. Peter Manabaru era además artista. Otro aspecto clave de nuestra investigación fue aprender que la información que se da a un hombre o a una mujer puede ser muy diferente, ya que hay controles sobre la dispersión de la información basados en el sexo. Por tanto, es posible que un hombre y una mujer que viven simultáneamente en una misma comunidad, tengan algunas áreas de conocimiento específicas de su sexo y otras compartidas. Esta diferenciación sexual en el acceso al conocimiento también afecta a los investigadores (Smith y Jackson 2005), lo que explica porque la información etnográfica recogida por etnógrafos y antropólogos hombres en los territorios de estudio, como Elkin (1952) o Macintosh (1977), no incluyera información relativa al conocimiento cultural de las mujeres. $\mathrm{Si}$ bien algunas de estas lagunas fueron abordadas por investigadoras como Phyllis Kaberry (1939) y Diane Bell (1993), que trabajaron principalmente con mujeres, esto no impidió el desarrollo de mitos arqueológicos, como la creencia de que las mujeres no producen arte rupestre (ver Smith 1991, para una refutación de esta creencia).

\section{c. Adaptación al concepto de tiempo Aborigen}

El concepto de tiempo occidental es distinto a los conceptos de tiempo Aborigen. El primero es lineal y lo visualizamos como una 'línea del tiempo', en la que el tiempo avanza hacia delante, y nos aleja progresivamente de un pasado cada vez más distante. Esta forma de pensar forma parte de nuestra tendencia a clasificar, separar y delimitar. Por el contrario, las tradiciones aborígenes hacen hincapié en las conexiones, las inter-dependencias y las relaciones. Para ellos el pasado no es realmente independiente del presente y sus nociones de tiempo están íntimamente ligadas al "Tiempo de los sueños" o la era de la creación, que continúa dando forma al presente y continuará en el futuro. Morphy (1998: 68) describe el Tiempo de los Sueños como "una dimensión de la realidad", así como "un período de tiempo" y señala "que es tanto una característica del futuro, como del pasado'. En esta visión del mundo, los seres ancestrales y los familiares fallecidos siguen presentes y tienen la capacidad de controlar y regular la forma adecuada de utilizar el territorio. Por ello, cuando los ancianos visitan lugares con arte rupestre que son particularmente importantes, llaman a estos seres espirituales, para informarles de la visita inminente.

¿Cómo afectan estos puntos de vista diferenciados a la investigación etnoarqueológica? Los investigadores debemos ser conscientes que el ritmo de vida y el nivel de precisión en cuanto al tiempo que se ha normalizado en las culturas occidentales tropieza con la resistencia de los Aborígenes. En varias ocasiones en que los Aborígenes no deseaban participar en nuestra investigación en ese momento la respuesta "lo haremos mañana" no significaba literalmente mañana. Significaba más tarde, tal vez mañana. Para investigadores que estamos bajo presión por recopilar datos, esto puede ser frustrante. Sin embargo, la capacidad de adaptarse a este tipo de desafíos puede marcar la diferencia entre el éxito y el fracaso.

\section{d. Flexibilidad frente a lo inesperado}

Relacionado con el punto anterior, en nuestro trabajo etnoarqueológico tenemos que estar abiertos a cambios de planes inesperados. Nuestra investigación es nuestra prioridad, pero no es necesariamente la prioridad de las personas con las que trabajamos. En alguna ocasión, cuando ya estaba todo preparado para ir a un yacimiento, de repente el coche se llenaba de mujeres Aborígenes que necesitaban transporte para ir a recoger hojas de pandanus para elaborar sus cestas. Las áreas de recolección de pandanus o de los colorantes utiliza- 
dos para teñir las fibras suelen estar a largas distancias de la comunidad. Por tanto, acceder a nuestros vehículos significa ahorrar tiempo y esfuerzo físico. Mientras que algunos investigadores pueden ver este repentino cambio de planes como una pérdida de tiempo, nosotros los aceptamos con una actitud abierta y como una forma de mostrar nuestro compromiso con la colaboración mutua. Es posible que a los Aborígenes también puede parecerles una pérdida de tiempo acompañarnos a los yacimientos o contarnos lo que para ellos es probablemente obvio. Por otra parte, esta y otras actividades inesperadas nos han proporcionado una gran experiencia socio-cultural que no habríamos tenido de haber impuesto nuestros horarios y metas. Gracias a este tipo de actividades no previstas, nuestra investigación etnoarqueológica va más allá del estudio del arte rupestre para incluir una exposición más amplia a las tradiciones y prácticas socio-culturales aborígenes, entre las que podemos incluir:

- ceremonias públicas y funerales, donde aprendemos sobre el comportamiento social,

- la adquisición de materia prima para la elaboración de cestas, la producción de didgeridoo, o la producción de arte sobre corteza de árbol, donde aprendemos acerca de la cultura, los usos del paisaje y los patrones de movilidad,

- incendios controlados del bosque, que nos enseñan acerca de la gestión Aborigen del paisaje, así como posibles tácticas de caza,

- la pesca,

- la recolección de miel, íntimamente relacionada con una de las técnicas de producción de arte rupestre documentada en estos territorios desde hace 4000 años, que consiste en la aplicación de cera de abeja sobre la roca para crear figuraciones) (Nelson et al. 1995), o

- simples paseos por el territorio, mientras aprendemos sobre la cultura.

Todas estas actividades no planificadas nos han proporcionado una imagen más completa de la cultura estudiada. Y mientras que algunos pueden pensar que estas actividades no están directamente relacionadas con el estudio de la producción y el consumo del arte rupestre (y por tanto con nuestro proyecto de investigación) debemos tener en cuenta que el arte rupestre es sólo una de las expresiones culturales de un grupo humano y que no puede entenderse aislada de la sociedad que lo produce. Además, la participación en estas actividades no planificadas nos ha proporcionado muchas veces un ambiente informal para aprender sobre la cultura (sin duda relacionada con el arte rupestre) y para mostrar nuestro compromiso con las necesidades de las personas que también invierten su tiempo en nosotros.

\section{e. Aprender cuándo es apropiado preguntar}

En el área en que trabajamos es importante saber cuándo callar y cuándo es apropiado preguntar. En nuestras investigaciones en la zona aprendimos que si una pregunta no es respondida puede deberse a varias opciones: 1) la persona a la que se está cuestionando no tiene la respuesta; 2) no tiene derecho a comunicar la respuesta; o 3) tu no tienes derecho a saber la respuesta. En nuestras investigaciones sobre arte rupestre, que es de las manifestaciones culturales de estos grupos que podríamos calificar de culturalmente sensibles, es decir, que no todo el mundo tiene derecho a conocer sus significados, somos conscientes de que existía información confidencial reservada a determinados sectores de la comunidad y, por tanto, de que nuestra posición social no nos permitiría acceder a ella. Esto nos ha sucedido a todas en alguna ocasión, especialmente cuando documentábamos escenas ceremoniales que contienen información restringida. En estos casos se nos proporcionó únicamente aquella información que se considera pública acerca de los detalles representados en las ceremonias (por ejemplo, May y Domingo 2010; Domingo 2011). En otra ocasión una de nosotras, siendo mujer, ingenuamente planeó entrevistar a los hombres acerca de diversas escenas en las que se representaba de forma explícita lo que parecía algún tipo de relación sexual. Y esta iniciativa, culturalmente inapropiada, causó muchas risas y ninguna respuesta. En estas situaciones en lugar de forzar la obtención de información restringida (que nunca nos darían), rediseñamos nuestras preguntas e investigaciones para incluir sólo datos públicos o para explorar cuestiones alternativas. De este modo respetamos las sensibilidades culturales y morales de las poblaciones con las que trabajamos, y al mismo tiempo resulta práctico, ya que los Aborígenes nunca nos revelarán esta información, del mismo modo que nosotros nos ne- 


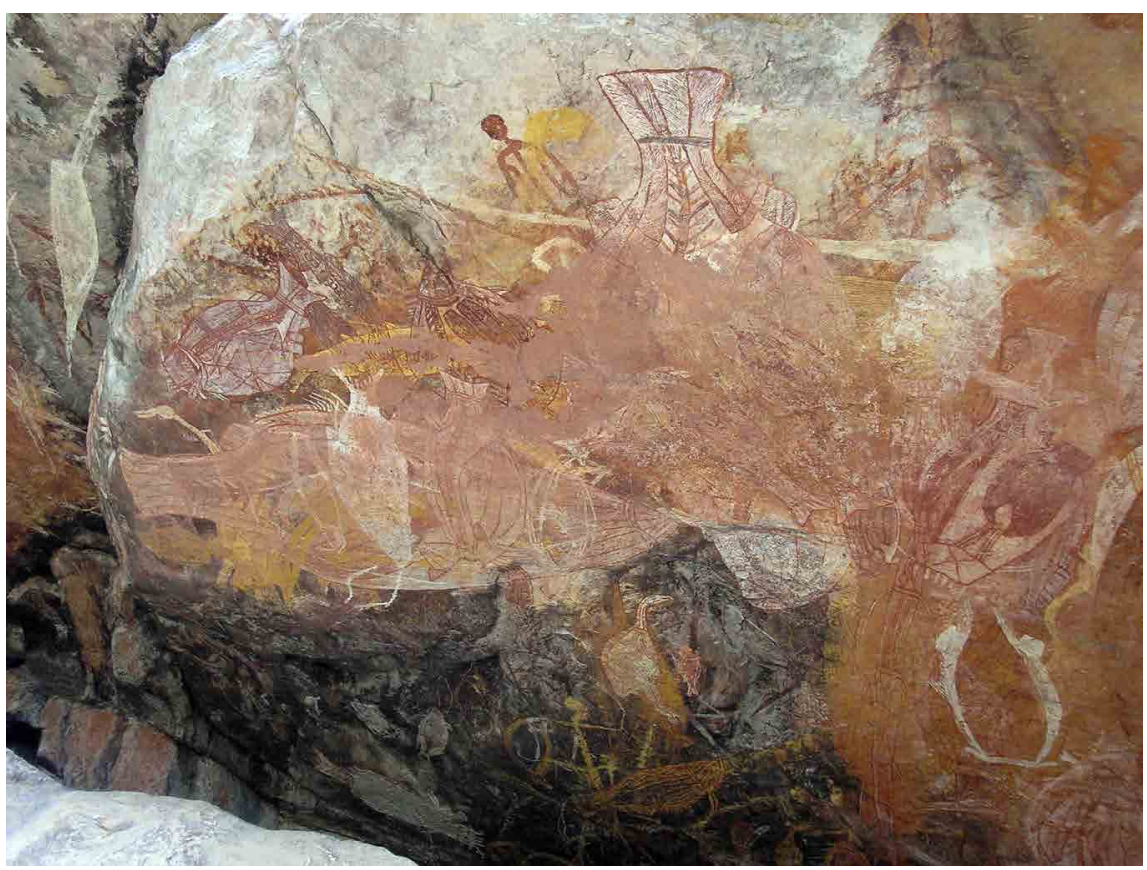

Figura 5. Arte rupestre de la colina de Injalak, con múltiples superposiciones en un mismo abrigo.

garíamos a revelar información confidencial. Respetar estas limitaciones nos permite continuar nuestras investigaciones y avanzar en el conocimiento del arte rupestre.

\section{f. No todo es publicable}

Obtener permiso para cualquier cosa que publicamos sobre las comunidades con las que trabajamos es una de nuestras premisas. Cuando trabajamos desde una perspectiva multitemporal (basada en repetidas visitas o largas estancias) comenzamos a participar en actividades y eventos no necesariamente vinculados con nuestra investigación, pero que nos pueden inspirar nuevos temas de análisis. En este contexto, un momento crítico es cuando comenzamos a participar en actividades culturales que no se pueden grabar o documentar, pero que pasan a formar parte de nuestra experiencia de vida. Esto incluye, por ejemplo, la asistencia a funerales donde puede ser culturalmente inapropiado fotografiar. En el pasado, ciertos investigadores publicaron de manera regular información secreta, considerando que las sociedades aborígenes (como tales) estaban muriendo y que la información debía estar disponible para los científicos y las generaciones futuras. Estas acciones causaron grandes traumas, no sólo para los aborígenes, sino también para los propios investigadores cuando años después se han puesto en evidencia sus transgresiones. Un ejemplo bien conocido es la orden de devolver y retirar del mercado el libro de Charles Mountford Nomads of the Australian Desert, que contenía información secreta-sagrada sobre prácticas ceremoniales en Australia central (Davis 2001). En el caso conocido como Foster contra Mountford, Charles Mountford fue declarado culpable de haber violado la confianza de los Aborígenes al haber publicado información y fotos de ceremonias secretas (Foster vs Mountford 197629 FLR 233).

Es importante ser consciente de que la frontera entre información restringida e información abierta es difusa. En las sociedades aborígenes la información se comparte de acuerdo con el contexto, que incluye no sólo a gente compartiendo conocimientos, sino también el lugar en el que se comparten. Existe la expectativa de que el receptor del conocimiento va a tratarlo correctamente y con respeto. Recientemente, una de nosotras recibió nuevos conocimientos acerca de prácticas ceremoniales que involucran a hombres y mujeres jóvenes. Esta información fue dada abiertamente, con una adolescente presente y varios niños cerca. Sin embargo, la investigadora (CS) tendría que pedir permiso explícito si quisiera compartir esos conocimientos en un foro público. Nuestra práctica es proporcionar a los Ancianos copias de los artículos y los libros que queremos 
publicar antes de su publicación, y leer en voz alta aquellos pasajes que pudieran ser críticos a quienes no pueden leer con facilidad. De esta manera, la obtención de una autorización protege tanto a la comunidad como al investigador, y asegura la supervivencia de las relaciones a largo plazo.

\section{Aplicaciones prácticas de la etnoarqueo- logía al estudio del arte rupestre}

Como arqueólogas estamos interesadas en el avance del conocimiento sobre el arte rupestre y la búsqueda de respuestas a las preguntas: quién, cuándo, dónde, cómo, qué y por qué. Nuestros métodos de investigación, desarrollados para responder a estas preguntas en contextos arqueológicos, pueden ser sin duda implementados mediante el análisis de las mismas cuestiones en un entorno etnoarqueológico. En este apartado exploramos brevemente algunas de estas preguntas (cuándo, cómo y qué) para demostrar cómo puede contribuir la etnoarqueología a mejorar nuestra aproximación arqueológica al arte rupestre y a plantear nuevos temas de investigación.

\section{a. ¿Cuándo?}

En arqueología resulta esencial poder asignar fechas específicas a tradiciones y estilos artísticos y construir cronologías relativas para analizar la evolución del arte y cuantificar cambios socio-culturales y medioambientales pasados. Junto a los métodos de datación numéricos, el análisis de las superposiciones es uno de los elementos clave para asignar motivos y temas a períodos distintos, establecer secuencias evolutivas e identificar momentos de cambio (Fig. 5).

En la Tierra de Arnhem, diversos investigadores han recurrido al análisis de las superposiciones para identificar cambios en las herramientas a largo de la historia (Lewis 1988) o cambios en la fauna local (Taçon 1989). Chaloupka por ejemplo, da un paso más allá y poniendo en relación superposiciones y cambios climáticos elaboró una propuesta evolutiva en la que sugiere marcos temporales específicos para distintas tradiciones artísticas en base a la fauna representada (Chaloupka 1993).

Pero ¿qué nos dice la etnoarqueología sobre el valor secuencial y clasificatorio de las superposiciones? Si un mismo grupo humano puede utilizar de forma paralela más de un es- tilo (Smith 1996) ¿cómo podemos determinar cuando un cambio estilístico marca una diferencia temporal y cuando refleja diversos contextos de producción o uso coetáneos? ¿Qué otros valores pueden tener las superposiciones y que otras preguntas inspiran su presencia?

Para los aborígenes de algunas partes de Australia, las superposiciones son una evidencia de la continuidad de una tradición iniciada por seres ancestrales en el pasado (Walsh 1988), pero que continua en el presente. La adición de nuevos motivos sobre otros previos no implica necesariamente una voluntariedad de marcar una separación cultural con lo anterior, sino de cumplir con su responsabilidad de cuidar el territorio y reavivar los valores culturales del lugar y sus relaciones con los espíritus y ancestros que los habitan (Smith 1996; Layton 2006). En ocasiones las superposiciones pueden ser indicativas de cambio, tanto para los arqueólogos como para los Aborígenes, pero para estos últimos son algo más que eso. Son un signo de continuidad cultural que nos recuerda y nos proporciona información sobre un aspecto pocas veces explorado en los estudios de arte rupestre antiguo: el proceso de consumo o reutilización del arte. Generalmente estamos tan obstinados en datar el momento exacto de producción que nos olvidamos que los motivos, temas y, sobretodo, los espacios con arte rupestre no eran utilizados de manera puntual, sino que eran reutilizados durante generaciones. Las representaciones previas eran sin duda percibidas por los nuevos artistas, que podían reutilizarlas tanto a nivel gráfico (para integrarlas en el nuevo discurso), como para ilustrar antiguos o nuevos relatos. Con estas observaciones no pretendemos insinuar que las superposiciones, que para los Aborígenes reflejan continuidad, tuvieran el mismo significado para los artistas del pasado. Pero si nos ayudan a plantear nuevas preguntas de investigación, como: ¿Con qué frecuencia y por cuánto tiempo se utilizó el arte rupestre? ¿Cómo interactúan los nuevos artistas con las manifestaciones previas? ¿Las superposiciones entre diversos motivos o estilos reflejan algo más que un simple cambio en las prácticas artísticas? ¿Qué evidencian las nuevas adiciones? ¿Una simple apropiación de los espacios culturales de otros grupos? ¿Cómo puede el arte rupestre ser signo de continuidad y de cambio al mismo tiempo? ¿Cómo puede ayudar la etnoarqueología a guiar nuestras preguntas y métodos? 
Un tema interesante en este sentido es la concepción que tienen las poblaciones Aborígenes actuales sobre el arte rupestre antiguo. Sin duda la presencia de representaciones previas evidencia la continuidad de esas prácticas culturales y las superposiciones les recuerdan el uso continuado de los mismos enclaves durante generaciones, y por tanto la importancia cultural de ese enclave. Pero lo más interesante es cómo algunos motivos datados hace cientos e incluso miles de años se siguen utilizando en la actualidad para compartir ideas, normas de comportamiento, relatos o tradiciones. En la colina de Injalak tenemos varios ejemplos. Uno de ellos es el que mostramos en la figura 6 . Se trata de la única representación figurativa conocida de Yingana, la Madre de la Creación, a la que se atribuyen diversos nombres dependiendo del dialecto local. Según cuenta la tradición, este Ser Ancestral, de gran importancia en estos territorios, viajó desde el norte cargando cestos que representan a los diversos clanes. En su viaje fue depositando estos cestos en diversos lugares, dando origen a los clanes, sus límites y sus dialectos. El Anciano Aborigen Jill Nganjmirra (Hamby 2005: 49) explicaba "Mi abuelo me contó esta historia. Todos esos cestos que carga en su cabeza, son todas las personas, de diferentes tribus y lenguas".

En la actualidad, esta representación sigue siendo una fuente de inspiración para los artistas aborígenes del centro de arte Injalak ${ }^{4}$. Es también una herramienta para continuar educando a los miembros de la comunidad local e incluso a los turistas sobre el papel que jugó Yirgana en la aparición de los aborígenes en la Tierra de Arnhem, quienes curiosamente también llegaron por el norte. Es interesante imaginar cómo habríamos interpretado esta imagen sin el contexto etnográfico y ver la continuidad en el uso a largo plazo de una imagen rupestre.

Otro ejemplo interesante es el que describimos en Domingo, 2011, escena 3. Se trata de una escena con figuras del estilo Mountford, que Chaloupka (1993:132) atribuye a la transición pleistoceno-holoneno, en la que un hombre a la carrera es perseguido por 4 mujeres. Si bien es posible que la lectura actual de la escena difiera de la original, resulta interesante observar como la distribución de las figuras "hombre delante y mujeres detrás" seguía resultando culturalmente significativa para los artistas locales Jimmy Galareya and Wilfred Nawirridj. Ambos nos indicaron que una dan-

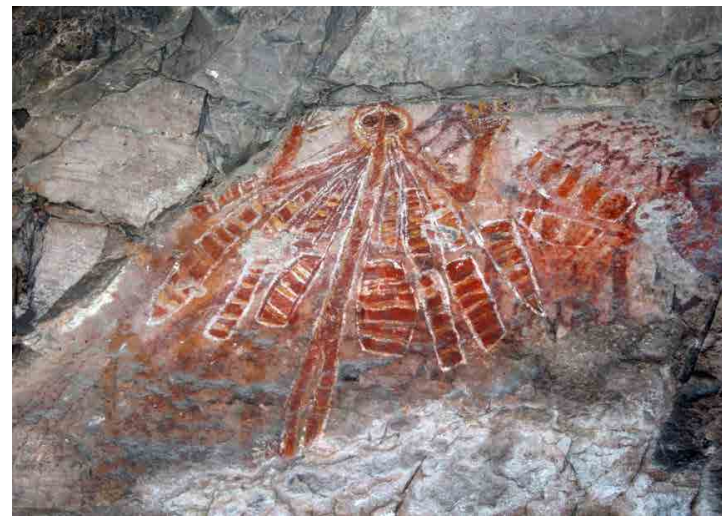

Figura 6. Madre de la creación, conocida localmente como Yirgana (colina de Injalak).

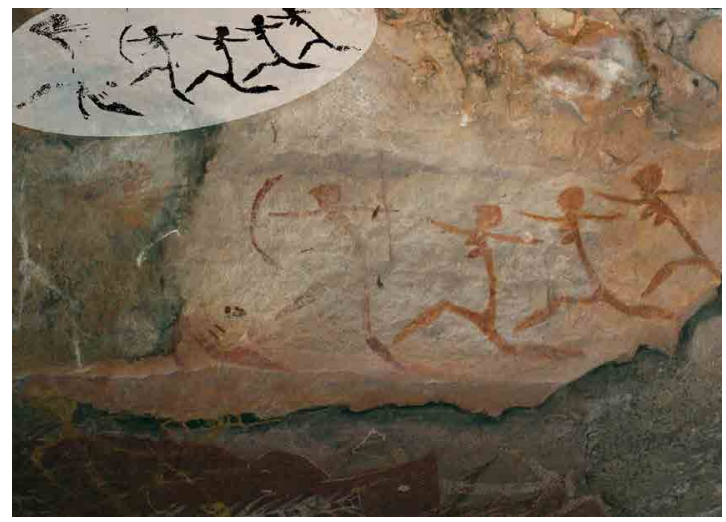

Figura 7. Escena de la colina de Injalak, en la que cuatro mujeres de estilo Mountford (con cuerpos alargados y movimientos exagerados) persiguen a un hombre. Calco digital por I. Domingo.

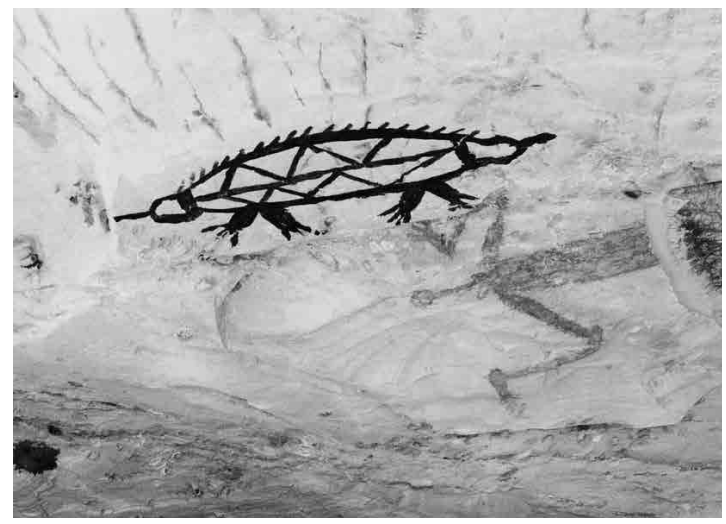

Figura 8. Yalkmurlering. Motivo pintado por Peter Manabaru. 
za en la que participen hombres y mujeres es característica de diferentes tipos de carroborees, o ceremonias de intercambio de regalos, y que esta escena es un buen recordatorio visual del comportamiento de género adecuado cuando ambos sexos participan en una danza. Por tanto, a pesar de su antigüedad esta escena sigue transmitiendo valores culturales utilizados para garantizar el mantenimiento de normas de comportamiento social ancestrales (Fig. 7). Esta explicación, que demuestra la continuidad del uso de algunas muestras de arte rupestre antiguo, también revela un papel del arte rupestre distinto al globalmente admitido, el valor simbólico. Nos referimos a su rol como vehículo para mantener el orden social.

Otra cuestión crítica en relación con el tema temporal es la que se refiere a la longevidad de las pinturas. ¿Por qué algunas pinturas sobreviven durante cientos, y a veces miles de años, mientras otras se desvanecen? El documental producido por C. Smith ofrece datos interesantes en este sentido (Smith 1992). Algunas de las pinturas que fueron creadas para el documental todavía se conservan en la actualidad y parecen tan frescas como cuando fueron pintadas (Fig. 8), mientras otras desaparecieron en pocos años. Esta diferencia en la longevidad está condicionada por el uso de agentes aglutinantes, que a su vez está relacionada con la dificultad de obtener dichos aglutinantes. Para la realización del documental se obtuvo el jugo de una orquídea que se encuentra en la parte alta de los árboles. Pero la cantidad recogida sólo fue suficiente para las primeras representaciones, mientras que el resto se realizaron sin aglutinante. Curiosamente los motivos realizados sin aglutinante desaparecieron. Este dato es interesante por diversas razones. En primer lugar nos informa del papel de los aglutinantes, no sólo para favorecer la adhesión del pigmento, sino también para su conservación. Pero además nos ayuda a reflexionar sobre la parcialidad del registro arqueológico. Mientras que las evidencias que han perdurado pueden ser analizadas a través de diversos métodos, poco podemos hacer frente a las evidencias perdidas. A través de la etnoarqueología es posible identificar qué tipos de datos pueden estar ausentes en el registro arqueológico.

\section{b. ¿Cómo?}

Otra área clave en la investigación sobre arte rupestre es el análisis del proceso de produc- ción (adquisición de materias primas, herramientas, preparación de pigmentos, colores predominantes, etc). Mientras que algunos aspectos del proceso pueden ser analizados a través de la arqueometría - el análisis de pigmentos, en ocasiones el uso de aglutinantes, etc.- otros pueden ser arqueológicamente invisibles, y es necesario recurrir a la arqueología experimental o a la etnoarqueología para poder reconstruir el proceso.

Un buen ejemplo lo encontramos al analizar las técnicas de aplicación de la pintura. En España el análisis del grosor de los trazos de los motivos rupestres del arte Levantino combinados con la arqueología experimental llevaron a Alonso y Grimal a sugerir la pluma como el único pincel posible utilizado por los artistas levantinos (Alonso y Grimal 1996: 194-196). Sus experimentos con fibras vegetales no fueron demasiado satisfactorios, y a pesar de que uno de ellos es artista no consiguió obtener bordes bien definidos y experimentó ciertas dificultades en el diseño de líneas curvas. Por el contrario, su experiencia con pelo animal fue más positiva, pero descartaron su utilización argumentando la dificultad que conlleva su elaboración (Domingo 2005: 107-108). Curiosamente, tanto la etnoarqueología como la etnografía proporcionan datos para poner en duda dicha interpretación.

En primer lugar, la supuesta incapacidad de las sociedades pre-industriales para producir pinceles con pelo animal subestima las capacidades técnicas de grupos humanos perfectamente capaces de aprovechar los recursos del medio para elaborar los instrumentos necesarios para sus actividades diarias. Por otra parte, las colecciones etnográficas australianas de diversos museos (como el South Australian Museum de Adelaida) y los estudios de varios investigadores (Morwood 2002: 112; Flood 1997: 16-17) demuestran que la producción de todo tipo de pinceles, realizados con materiales tales como las plumas, herbáceas machacadas, corteza de árbol, raíces, así como de pelos de animales y de cabello humano, era común.

En nuestro trabajo de campo en Gunbalanya y Barunga tuvimos la ocasión de documentar el proceso de producción y uso de diversos tipos de pinceles efectuados con herbáceas, con los que es posible producir trazos tan finos y modelantes como los del arte rupestre Levantino (Fig. 9). En base a nuestras observaciones etnográficas podemos afirmar que artistas experimentados con buenas habilida- 

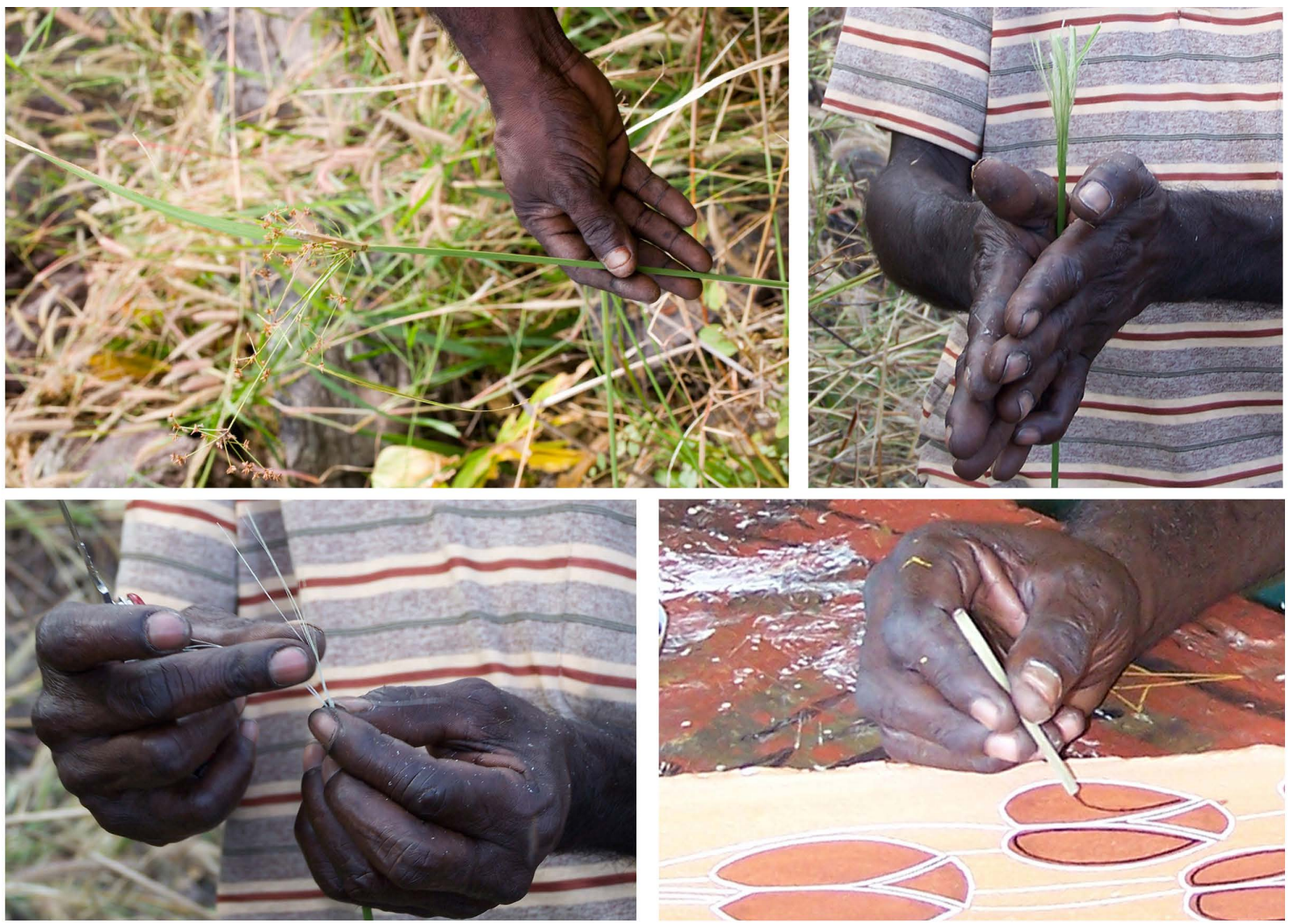

Figura 9. Artista local mostrando el proceso de fabricación de un pincel vegetal.

des técnicas pueden producir perfectamente líneas finas y delicadas como las observadas en el arte rupestre Levantino con este tipo de pinceles (Fig. 6). Esto deja abierta la posibilidad de su uso en la prehistoria por parte de los artistas Levantinos y nos permite rechazar la hipótesis de Alonso y Grimal sobre el uso de la pluma como el único tipo de pincel utilizado para producir arte Levantino. Por tanto, en esta ocasión la etnoarqueología nos ha servido para descartar propuestas interpretativas basadas en la experimentación y en ciertos prejuicios sobre las capacidades tecnológicas de sociedades pasadas.

La etnoarqueología también nos permite recordar la parcialidad del registro arqueológico cuando hablamos de las técnicas de representación en el arte rupestre. Es posible que aquellos materiales y colores más perecederos (como por ejemplo el color blanco) estén mal representados en el registro arqueológico actual, no por falta de uso en el pasado sino por sus problemas de conservación (Chaloupka 1993; Chippindale y Taçon 1998b; Domingo et al, en prensa). En el Territorio del Norte se ha documentado una técnica de representación única: la cera de abeja, con serios problemas de conservación a largo plazo. Esta técnica consiste en la aplicación de bolas, tiras u hojas de cera de las abejas nativas de Australia sobre una superficie rocosa para producir diversos tipos de diseños (Brandl 1968: 19). Las evidencias más antiguas datan de hace 4000 años (Nelson et al 1995; Nelson 2000; Nelson et al 2000) (Fig. 10), pero la fragilidad de la cera, que se cuartea y desprende con facilidad al secarse, nos impide constatar si se utilizó con anterioridad, tanto en Australia como en otros lugares. Con este ejemplo no pretendemos sugerir el uso de la cera de abeja para la producción de arte rupestre en la prehistoria, ni en Australia ni en cualquier otro lugar. Nuestra idea es resaltar cómo la etnoarqueología nos recuerda la necesidad de ser más críticos y tener en cuenta este tipo de limitaciones a la hora de cuantificar y evaluar el papel de los diversos colores y técnicas en el pasado, ya que los patrones de degradación de las diversas técnicas y colores podrían estar ofreciendo una visión distorsionada del arte rupestre antiguo y llevarnos a conclusiones erróneas sobre prácticas culturales pasadas. 



Figura 10. Motivo de cera de abeja de Ingaanjalwurr (Oeste de la Tierra de Arnhem) y miembro de la comunidad local mostrando la recolección de cera y miel de abeja.

c. ¿Qué?

La descripción y clasificación del arte, para identificar tradiciones artísticas, y el tema de la interpretación son también objeto de investigación en arqueología. Esta es una de las áreas para las que la etnoarqueología puede aportar más datos para evaluar las limitaciones de enfoques puramente arqueológicos. Nuestras investigaciones etnoarqueológicas nos ha demostrado que una plena comprensión de los motivos, las tradiciones y las actividades representadas, así como las reglas y normas socio-culturales reproducidas en los paneles, sólo puede lograrse a través de una completa comprensión de las culturas que produjeron el arte (May y Domingo 2010; Domingo 2011; Domingo et al. 2016; Smith et al. en prensa). Incluso el nivel más básico, la identificación de motivos figurativos, es problemático si carecemos de conocimientos locales. Algo que ya demostró Macintosh en su célebre artículo sobre el yacimiento de Doria Gudalak, en Barunga (Macintosh 1977), en el que malinterpretó el $90 \%$ de las especies representadas. Si la identificación literal de los motivos puede ser complicada, aún es más delicado intentar descifrar el significado. Por ejemplo, ¿qué representa un antropomorfo? ¿Se trata de una persona real, un antepasado, un espíritu maligno? ¿o no tiene nada que ver con lo humano? Como señala Morphy, existe una brecha significativa entre los motivos representados y los conceptos culturales que re- presentan (Morphy 1989). Por tanto, descifrar el arte de otra cultura sin la asistencia de una persona informada será complicado y, en la mayoría de los casos, corremos el peligro de caer en la esfera de la especulación.

El trabajo de T. Yulidjirri en la década del 2000 nos servirá para ilustrar este aspecto (véase May 2006; May 2008). Como artista Aborigen experimentado y residente en Gunbalanya era responsable de enseñar a los artistas jóvenes los métodos y reglas que regulan la producción artística, y las historias que se esconden detrás de estas creaciones. Para T. Yulidjirri el arte tiene una finalidad educativa $y$, un ojo no entrenado, será incapaz de diferenciar entre dos de sus cuadros. Aunque a simple vista podrían resultar similares, al incluir figuras humanas simples con o sin cultura material (como una lanza), las historias que se esconden detrás podrían ser muy diferentes. Del mismo modo, una misma representación podría utilizarse para narrar diversas historias (Fig. 11). Yulidjirri describe las pinturas como una puerta de entrada para explorar y comunicar las creencias culturales y los seres ancestrales de su cultura. Este artista creció en conexión con su territorio experimentándolo de manera directa (lo que llaman Walking country) y fue aleccionado por uno de los últimos grandes pintores rupestres (Paddy Compass Namatbara). Por ello, su obra constituye un ejemplo fascinante de la complejidad que comporta la interpretación del arte rupestre antiguo. 
Los ejemplos presentados a lo largo de estas líneas muestran sólo algunas de las múltiples esferas de análisis y reflexión que nos permite una aproximación etnoarqueológica. Estos ejemplos permiten demostrar el potencial de la etnoarqueología para proponer métodos de análisis del arte antiguo más críticos a la hora de explorar y responder a las preguntas: dónde, por qué, quién, qué, cómo, etc., o de analizar la diversos aspectos de los procesos de producción y el consumo del arte rupestre, tanto a nivel material como socio-cultural.

\section{Conclusiones}

En este trabajo hemos analizado de forma crítica el potencial, las perspectivas y las implicaciones éticas de una aproximación etnoarqueológica al arte rupestre, en base a nuestra experiencia personal en varias comunidades Aborígenes del oeste y el sur de la Tierra de Arnhem (Australia). El trabajo cuestiona los usos y asunciones que se han hecho de la analogía en el pasado para interpretar el arte rupestre antiguo. Todos sabemos los peligros que conlleva la utilización de relatos etnográficos actuales para interpretar el arte rupestre de otras culturas separadas en el tiempo y en el espacio. Este trabajo también advierte de que la asunción de que el supuesto estancamiento de las sociedades Aborígenes en el tiempo puede proporcionar información sobre el pasado de la humanidad, es totalmente errónea y está basada en ideologías racistas.

En nuestra opinión queda más que demostrado que el tema de la interpretación del arte rupestre antiguo se encuentra en la esfera de la especulación, y que la etnoarqueología poco puede contribuir al respecto, excepto para demostrar que el significado es inalcanzable sin la ayuda de informantes. Los ejemplos analizados en este artículo - con las experiencias de los Ancianos T. Yulidjirri, Jill Nganjmirra, y P. Manabaru - permiten mostrar la complejidad de las prácticas, los mensajes y los significados que se esconden detrás del arte rupestre. Lo que plantea un desafío para los arqueólogos, ya que nos obliga a replantearnos las posibilidades y limitaciones de los enfoques puramente arqueológicos y especialmente las interpretaciones simplistas sobre estas manifestaciones artísticas. Pero los estudios de arte rupestre van más allá de la búsqueda de significado. Y hay muchos otros aspectos del proceso

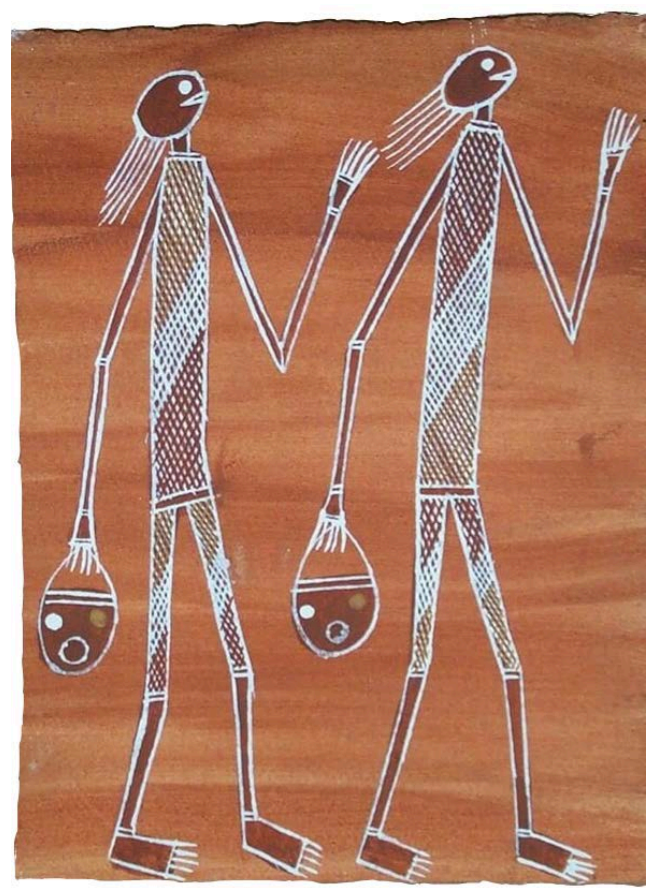

Figura 11. Hombres Waralak pintados por Thompson Yulidjirri, 2002.

de producción (materias primas, herramientas, pigmentos, etc.), de los contextos de uso e incluso del abandono, así como de las prácticas socio-culturales vinculadas a cada una de estas fases, a los que puede contribuir un estudio etnoarqueológico del arte rupestre, como demuestran los ejemplos tratados.

Nuestra experiencia etnoarqueológica en el área de estudio, aprendiendo de Ancianos y artistas Aborígenes con conocimientos sobre el arte reciente de sus tierras tradicionales, ha resultado útil para avanzar en la comprensión del arte rupestre en un contexto vivo y para rediseñar nuestros métodos de investigación arqueológica del arte. Pero además, a nivel personal, también ha sido una experiencia muy satisfactoria. Gran parte de nuestros resultados son útiles no sólo para el avance del conocimiento científico sino también para las poblaciones con las que trabajamos, al proporcionarles registros detallados que incluyen todos sus yacimientos arqueológicos y con arte rupestre. Esto ha contribuido a mejorar la gestión y conservación de los yacimientos y, en algunos casos, a encontrar argumentos solidos para garantizar la protección a largo plazo del territorio contra fuerzas e intereses políticos y económicos de gran alcance. 


\section{Agradecimientos}

Las reflexiones presentadas en este trabajo han sido posibles gracias a la colaboración de mucha gente a lo largo de estos años, tanto Aborígenes como no Aborígenes. Agradecemos a los Propietarios Tradicionales, pasados y presentes, de las comunidades Aborígenes en las que hemos trabajado por darnos permiso para realizar nuestras investigaciones en sus tierras durante muchos años. También agradecemos a los co-investigadores de los proyectos relacionados, particularmente a Paul Taçon y Gary Jackson.

Agradecemos entre otros a Injalak Arts and Crafts, Felicity Wright, Anthony Murphy, al Northern Land Council, a Gabriel Maralngurra, Isaías Nagurrgurrba, Thompson Yulidjirri y Wilfred Nawirridj.

Nuestras investigaciones a largo plazo en esta región han sido financiadas por diversas subvenciones públicas: Australian Research Council Discovery DP0453101, Australian National University y Flinders University y el Ministerio Español de Ciencia e Innovación.

Por último agradecemos a Jordan Ralph que proporcionó una copia de este artículo a los ancianos de Barunga y a Nell Brown, junggayi, por darnos permiso para publicar sobre las investigaciones hechas en Barunga.

\section{Notas}

4. Injalak arts es una organización de una comunidad Aborigen sin ánimo de lucro que da apoyo a los artistas en la producción de arte pintado y objetos de fibra. Está en la comunidad de Gunbalanya, Oeste de la Tierra de Arnhem (Australia).

\section{Bibliografía}

Alonso, A.; Grimal, A. (1996): El Arte rupestre prehistórico de la cuenca del Río Taibilla (Albacete y Murcia): nuevos planteamientos para el estudio del Arte Levantino. Barcelona.

Bell, D. (1993): Daughters of the Dreaming. Allen and Unwin, Sydney.

Bernard, H.R. (2011): Research methods in anthropology: Qualitative and quantitative approaches. UK. Altamira Press.

Berndt R.M.; Berndt C.H. (1970): Man, land and myth in North Australia. The Gunwinggu people, Ure Smith, Sydney.

Binford, L.R. (1967): Smudge pits and hide smoking: the use of analogy in archaeological reasoning. American Antiquity, 32: 1-12.

Brady, L.M.; Bradley, J.J.; Kearney, A.J. (2016): Negotiating Yanyuwa Rock Art. Relational and Affectual Experiences in the Southwest Gulf of Carpentaria, Northern Australia. Current Anthropology, 57 (1): 28-52.

Brandl, E.J. (1968): Aboriginal rock designs in beeswax and description of cave painting sites in Western Australia. Archaeology and Physical Anthropology in Oceania, 3 (1): 19-29.

Breuil, H. (1952): Four hundred Years of Cave art. Montignac, Dordogne: Centre d'Études et de Documentation Préhistorique.

Chaloupka, G. (1981): The traditional movement of a band of Aboriginals in Kakadu. Kakadu National Park Education Resources (T. Stokes, ed.), Australian National Parks and Wildlife Service, Canberra: 162-171.

Chaloupka, G. (1993): Journey In Time: The 50000 Years Story Of Aboriginal Rock Art of Arnhem Land. Reed New Holland, Sydney.

Chippindale, C.; Taçon, P. (eds.) (1998): The Archaeology of Rock-Art. Cambridge University Press, Cambridge.

Clarke, P. (2003): Where the ancestors walked. Allen and Unwin, Sydney.

Clarkson, C.; Smith, M.; Marwick, B.; Fullagar, R.; Wallis, L.A.; Faulkner, P.; Manne, T.; Hayes, E.; Roberts, R.G.; Jacobs, Z.; Carah, X.; Lowe, K.M.; Matthews, J.; Florin, S.A. (2015): The archaeology, chronology and stratigraphy of Madjedbebe (Malakunanja II): A site in northern Australia with early occupation. Journal of Human Evolution, 83: 46-64.

Clifford, J. (1988): The Predicament of Culture: Twentieth Century Ethnography, Literature and Art. Harvard University Press, Cambridge.

Clottes, J.; Lewis-Williams, D. (1996): Los chamanes de la prehistoria, tránsito y magia en las cuevas decoradas. Ariel, Barcelona.

David, B.; Barker, B.; Petchey, F.; Delannoy, J.J; Geneste, J.M.;Rowe, C.;Eccleston, M.;Lamb, L.; Whear, R. (2013): A 28,000 year old excavated painted rock from Nawarla Gabarnmang, northern Australia. Journal of Archaeological Science, 40: 2493-2501. 
David, N.; Kramer, C. (2001): Ethnoarchaeology in Action. Cambridge, Cambridge University Press.

Davis, M. (2001): Law, anthropology and the recognition of Indigenous cultural systems. Law and Anthropology (R. Kuppe, R. Potz, eds.), Kluwer Law, The Hague: 298-320.

Domingo, I. (2005): Técnica y ejecución de la figura en el arte rupestre Levantino. Hacia una definición actualizada del concepto de estilo: validez y limitaciones. Tesis Doctoral. Servicio de Publicaciones Universitat de Valencia, Valencia.

Domingo, I. (2011): The rock art scenes at Injalak Hill: alternative visual records of Indigenous social organisation and cultural practices. Australian archaeology, 72: 15-22.

Domingo, I.; May S.K. (2008): La pintura y su simbología en las comunidades de cazarecolectores de la Tierra de Arnhem. Mundos Tribales: Una Visión Etnoarqueológica (J. Salazar, I. Domingo, J. Azkárraga, H. Bonet, eds.). Museu de Prehistoria, Valencia: 78-91.

Domingo, I.; May, S.K.; Smith, C. (2016): Communicating through rock art: an ethnoarchaeological perspective. Signes et communication dans les civilisations de la parole, Edition electronique du CTHS (Actes des congres des sociétés historiques et scientifiques) (O. Buchsenschutz, C. Jeunesse, C. Mordant, D. Vialou, dir.), París: 9-26.

Domingo, I.; May, S.K.; Smith, C. (en prensa): Etnoarqueología y arte rupestre en el siglo XXI: de la analogía directa a la redefinición del método arqueológico. Redescubriendo el Arte Parietal Paleolítico. Últimas novedades sobre los métodos y las técnicas de investigación. Kobie (Serie Anejos) 15, 2016.

Elkin, A.P. (1952): Cave paintings in southern Arnhem Land. Oceania, 22: 245-55.

Field, J.; Barker, J.; Barker, R.; Coffey, E.; Coffey, L.; Crawford, E.; Darcy, L.; Fields, T.; Lord, G.; Steadman, B.; Colley, S. (2000): 'Coming back' Aborigines and archaeologists at Cuddie Springs. Public Archaeology, 1: 35-48.

Flood, J. (1997): Rock art of the Dreaming. Images of Ancient Australia. Angus and Robertson, Sydney.

Foster v Mountford 197629 FLR 233:286.

Frazer, J.G. (1922): The Golden Bough. A Study in Magic and Religion. Macmillan, New York.

González-Ruibal, A. (2007): De la etnoarqueología a la arqueología del presente. Mundos Tribales: Una Visión Etnoarqueológica (J. Salazar, I. Domingo, J. Azkárraga, H. Bonet, eds.). Museu de Prehistoria, Valencia: 16-27.

Gould, R. (1978): Beyond analogy in ethnoarchaeology. Explorations in ethnoarchaeology (R.A. Gould, ed.), University of New Mexico, Albuquerque: 249-293.

Greer, S. (2014): The Janus View: Reflections, Relationships and a Community-Based Approach to Indigenous Archaeology and Heritage in Northern Australia. Journal of Community Archaeology \& Heritage, 1(1): 56-68.

Greer, S.; Harrison, R; McIntyre-Tamwoy, S. (2002): Community-based archaeology in Australia. World Archaeology, 34(2): 265-287.

Griffiths, T. (1996): Hunters and Collectors, Cambridge University Press, Cambridge.

Hamby, L. (2005): Twined Together, Kunmadj Njalehnjaleken.Injalak Arts and Crafts, Gunbalanya.

Hernando, A. (1995): La etnoarqueología hoy: una vía eficaz de aproximación al pasado. Trabajos de Prehistoria, 52 (2): 15-30.

Idriess, I.L. (1963): Our living Stone Age. Angus \& Roberston, Syndey.

Kaberry, P. (1939): Aboriginal Woman. Sacred and Profane. Routledge and Keagan Paul, London.

Lamshed, M. (1972): Monty: A biography of CP. Mounfort. Rigby, Adelaide.

Layton, R. (1992): Australian Rock Art: a new synthesis. Cambridge University Press, Cambridge.

Layton, R. (2006): Habitus and narratives of rock art. Talking with the past. The ethnography of rock art (J. Keyser, G. Poetschat, M.W. Taylor, eds.), The Oregon Archaeological Society, Oregon: 73-99.

Lecompte, M.D.; Schensul, J.J. (2015): Ethics in Ethnography. A mixed methods approach. UK. Altamira press.

Lewis, D. (1988): The rock paintings of Arnhem Land, Australia: social, ecological and material culture change in the Post-Galcial preiod. BAR International Series 415.

Macintosh, N.G.W. (1977): Beswick Creek Cave two decades later: a reappraisal. Form in indigenous art (P.J. Ucko, ed.) Australian Institute of Aboriginal Studies, Canberra: 191-97.

May, S.K. (2000): The Last Frontier? Acquiring the American-Australian Scientific Expedition Ethnographic Collection 1948, Trabajo de Investigación inédito (Honours), Flinders University of South Australia.

May, S.K. (2006): Karrikadjurren: creating community with an art centre in Indigenous Australia. Tesis Doctoral inédita, Australian National University.

May, S.K. (2008): Learning Art, Learning Culture: Art, Education, and the Formation of New Artistic Identities in Arnhem Land, Australia. Archaeologies of Art: time, place and identity. (I. Domigno, S.K. May, D. Fiore, eds.) Left Coast Press, Walnut Creek CA: 171-194.

May, S.K. (2009): Collecting Cultures: myth, politics and collaboration in the 1948 Arnhem Land Expedition, AltaMira Press, Lanham MD USA.

May, S.K.; Domingo, I. (2010): Making sense of scenes. Rock Art Research, 27:35-42. 
May, S.K.; Domingo, I.; Taçon, P. (2015): Arte rupestre de contacto: la version Indígena de los encuentros interculturales en el noroeste de la Tierra de Arnhem (Australia). La vitalidad de las voces Indígenas: arte rupestre del contacto y en sociedades colonials. (F. Berrojadil, eds.) Instituto de Investigaciones Estéticas de la Universidad Nacional Autónoma de México, México.

May, S.K.; Gumurdul, D.; Manakgu, J.; Maralngurra, G.; Nawirridj, W. (2005) You write it down and bring it back... That's what we want. Revisiting the 1948 removal of human remains from Kunbarlanja (Oenpelli), Australia. Indigenous Archaeologies: Decolonising Theory and Practice. (C. Smith, M. Wobst, eds.). Routledge, London: 102-121.

McNiven, I.; Russell, L. (2005): Appropriated Pasts: Indigenous Peoples and the Colonial Culture of Archaeology. AltaMira Press, Walnut Creek, CA.

Moro Abadía, O.; González Morales, M. R. (2005): L'analogie et la représentation de l'art primitif à la fin du XIXe siècle. L'Anthropologie, 109 (4): 703-721.

Morphy, H. (1989): Introduction. Animals into art (H. Morphy, ed.) Unwin Hyman, London: 1-17.

Morphy, H. (1991): Ancestral Connections: art and an Aboriginal system of knowledge. University of Chicago Press, Chicago.

Morphy, H. 1998 Aboriginal Art. London, Phaidon Press.

Morwood, M. (2002): Visions from the Past. The Archaeology of Australian Aboriginal Art. Allen \& Unwin, Sydney.

Mountford, C.P. (1949): Exploring stone age Arnhem Land. National Geographic, 96(6): 745-82.

Mountford, C.P. (1963): Australia's Stone Age men. Great adventures with National Geographic. National Geographic Society, Washington DC: 385-392.

Mountford, C.P. (1976): Nomads of the Australian Desert. Rigby, Adelaide.

Nelson, D.E. (2000): The Beeswax Art of Northern Australia. Simon Fraser University, Burnaby.

Nelson D.E.; Chaloupka, G.; Chippindale, C.; Alderson, M.S.; Southon, J.R. (1995): Radiocarbon dates for beeswax figures in the prehistoric rock art of northern Australia. Archaeometry, 37 (1): 151-156.

Nelson, D.E.; Chippindale, C.; Chaloupka, G.; Taçon, P.S.C. (2000): The plateau sites. The Beeswax Art of Northern Australia (D.E. Nelson, ed.) Simon Fraser University, Burnaby: 67-82.

Nietzche, F. (1974): Thoughts Out of Season, Part 2, Gordon Press, New York.

Politis, G. (2002): Acerca de la etnoarqueología en América del Sur. Horizontes Antropológicos, 8 (18): 61-91.

Politis, G. (2015): Reflections about Contemporary Ethnoarchaeology. Pyrenae, 46 (1): 41-83.

Politis, G. (2014): Ethnoarchaeology: Approaches to Fieldwork. Encyclopedia of Global Archaeology (C. Smith, ed.), Springer, New York: 2530-2535.

Ripoll, E. (1986): Orígenes y significado del arte Paleolítico. Sílex ediciones, Madrid.

Reinach, S. (1903): L'art et la magie: À propos des peintures et des gravures de l'Âge du Renne". L'Anthropologie, 14: 257-66.

Rosenfeld, A. (1997): Archaeological signatures of the social context of rock art production. Beyond Art: Pleistocene Image and Symbol, Memoirs of the California Academy of Science 23. (M. Conkey, O. Soffer, D. Stratmann, N.G. Jablonski, eds.).

Smith, C. (1991): Female artists: the unrecognised factor in sacred rock art production. Rock art and prehistory (P. Bahn, A. Rosenfeld, eds.). Oxbow Press, Oxford: 45-52.

Smith, C. (1992): Jungayi. Caring for Country. Video documental.

Smith, C. (1996): Situating Style. An ethnoarchaeological study of social and material context in an Australian Aboriginal artistic system. Tesis Doctoral Inédita. University of New England.

Smith, C. (2004): Country, kin and culture: survival of an Australian Aboriginal community. Wakefield Press, Kent Town.

Smith, C. (2008): La supervivencia de las culturas Indígenas. Mundos tribales. Una visión etnoarqueológica (J. Salazar, I. Domingo, J. Azkárraga, H. Bonet, eds.) Museo de Prehistoria de Valencia. Valencia.

Smith, C.; Jackson, G. (2005): Living and Learning on Aboriginal Lands: Decolonising Archaeology in Practice. Indigenous Archaeologies: Decolonising Theory and Practice. (C. Smith, H.M. Wobst, eds.) Routledge, London: 336-349.

Smith, C.; Copley, V.; Jackson, G. (en prensa): On the reformulation and repatriation of Indigenous knowledge. Increasing Heritage Awareness (V. Apaydin, J. Jameson, eds.) Springer, New York.

Smith, C.; Domingo, I.; Jackson, G. (2016): Beswick Creek Cave six decades later: change and continuity in the rock art of Doria Gudaluk. Antiquity, 90 (354): 1613-1628.

Smith, L. (1999): Decolonizing Methodologies: Research and Indigenous Peoples. Zed Books, London.

Spencer, B. (1901): Guide to the Australian Ethnographic collection in the National Museum of Victoria. Government printer, Melbourne.

Taçon, P.S.C. (1989): From the Dreamtime to the present: the changing role of aboriginal rock paintings in Western Arnhem Land, Australia. The Canadian Journal of Native Studies, IX (2): 317-339. 
Taçon, P.S.C.; Garde. M. (1995): Kun-Wardde Bim: rock art from western and central Arnhem Land. Rainbow, sugarbag and moon: two artists of the stone country: Bardayal Nadjamerrek and Mick Kubarkku. (M. West, ed.) Museum and Art Gallery of the Northern Territory Darwin, Australia: 30-36.

Taçon, P.S.C.; Kelleher, M.; King, G.;W. Brennan. (2008): Eagle's Reach: a focal point for past and present social identity within the northern Blue Mountains World heritage area, New South Wales, Australia. Archaeologies of art: time, place and identity (I. Domingo, D. Fiore, S.K. May, eds.), Left Coast Press, Walnut Creek: 195-214.

Taylor, G. (1927): Environment and race. Oxford University Press, Oxford.

Taylor, L. (1996): Seeing the Inside: Bark Painting in Western Arnhem Land. Clarendon Press, Oxford.

Tylor, E.B. (1865). Researches into the Early History of Mankind and Development of Civilization. John Murray, London.

Tylor, E.B. (1871): Primitive Culture: Researches into the Development of Mythology, Philosophy, Religion, Language, Art and Custom. (Reeditado en español Tylor, E. B. (1976): Cultura primitiva: Los orígenes de la cultura. Ayuso).

Van Reybrouck, D. (2012): From primitives to primates. A history of ethnographic and primatological analogies in the study of prehistory. Sidestone Press, Leiden.

Vizard, W.G. (1930): The Australian Stone Age Men. A Black People ask for a Fair Deal in a Fair country. Leader Publishing Co., Northcote, N.S.W.

Walsh, G.L. (1988): Australia's Greatest Rock Art. E.J. Brill/Brown and Associates, Australia.

Watkins, J. (2000): Indigenous Archaeology: American Indian Values and Scientific Practice. AltaMira Press, California.

Wilson, C. (2007): Indigenous Research and Archaeology: Transformative Practices in/with/for the Ngarrindjeri Community. Archaeologies: Journal of the World Archaeological Congress, 3(3): 320-334.

Wright, D.; May, S.K.; Taçon, P.; Stephenson, B. (2014): A scientific study of a new cupule site in Jabiluka, Western Arnhem Land. Rock Art Research, 31(1): 92-100.

Wolf, E. (1982): Europe and the People Without History. University of California Press.

Wylie, A. (1985): The reaction against analogy. Advances in archaeological method and theory, vol. 8. (M. B. Schiffer, ed.), Academic Press, New York: 63-111. 